\title{
Gender Discourses as a 'Technology of Power' in Nepalese Primary Level Textbooks
}

\author{
Pragya Paneru*
}

\begin{abstract}
The Gender gap is one of the most prominent problems in the context of Nepal. Even if Nepal constitution promotes gender equality and equity, there is still a huge gap between male and female. Women lag in literary percentage, nutritional health conditions, ownership, and employment opportunities. One of the obstacles in the path of gender equality is our systemic education materials especially our textbooks which reinforce the stereotypical concept of male and female through textbook representations. Researchers have shown that gender stereotypes have been seen in the textbooks of highly developed countries like America, Australia, and Hongkong. In this context, all the compulsory textbooks of grade four and five prescribed by the Curriculum Development Centre in the context of Nepal were observed. In all the books, stereotypical representations of male and female characters were found. Most of the men and women were presented doing conventional gender roles, and malecentered themes are foundin the narratives. This research claims that when conventional attitude regarding gender is transferred to young children, it ultimately reproduces similar gendered personalitiesand helps to maintain the gender gap. This research uses the concept of 'technology of power' by Foucault to interpret gender representations in textbooks. ACcriticalDiscourse Analysis has been used to analyze the data from textbooks. The findings suggest that there are biased gender representations suggesting stereotypes and gender binary which could potentially affect the learners both male and female as it fosters false knowledge regarding gender and overburdens the male whereas humiliates the females.
\end{abstract}

Keywords: stereotypes, representation, patriarchal, socialization, masculinity

\section{Introduction}

There are very few studies in the educational context in Nepal. Among the studies that have been conducted in textbooks gender representation in Nepal, female underrepresentation was found in all subject contexts of primary level and the

*Ms. Paneru has received Master's degree in English and Anthropology from Tribhuvan University and has been conducting research at University of Technology, Sydney, Australia as a part of Higher Degree Research Program. She is a lecturer in English at Nepal Commerce Campus, Tribhuvan University, Nepal 
organizational aspects were also dominated by males (Joshi \& Anderson, 1994). Studies also show that there is a gender gap in education in Nepal and this gap widens in rural areas and in higher education levels (Panthee\&McCutcheon, 2015; Khanal 2018). Unlike these researches, Shrivastava's comparative research in social studies textbooks of Pakistan, Bangladesh and Nepal (as cited in Blumberg, 2008) claims that women were invisible in the history related chapters in all three countries. However, in comparison to Bangladesh, and Pakistan Nepal's Social Studies textbooks were found better in the sense that they addressed women related problems (p. 15). A similar study by Rothchild (2007) conducted in Jiri, also shows that there were unequal social gender discourses among parents and teachers which pulled women away from equal access to opportunities and promoted the attitude of son preferences. This son preferences attitude also leads to sex-selective abortions in Nepal (Lammichhane et al., 2011). This gender discrimination in the Nepalese society is due to an unequal social understanding about males and females, male supremacy in the social structures, and due to legal causes (Upreti, 2016).

Gender representation in textbooks is an important issue and it is regarded as an important socializing agent(Gupta \& Lin, 1989). The way gender is represented in the textbooks can influence the world view of the learners and manipulate them accordingly. Since schools are also a significant site of cultural transformation where patriarchal social structure is intentionally implemented to transform it in the young generation(Blair 2002), to minimize the gender gap and promote gender justice, gender issues in the school education context should be addressed. Gender representation in the textbooks is regarded as a significant but an overlooked issue, and a potential issue contributing the perpetuation of the gender gap and gender stereotypes (Blumberg, 2008). There have been several political and social changes in Nepal possibly leading to many changes in the textbook's contents however there are no much studies in this field. This article explores the present context of gender discourses in primary level textbooks in Nepal to address this gap.

This research especially investigates the current gender issues in the Nepalese primary level textbooks and the gender discourses within the language and images through critical discourse analysis applying Foucault's concept, discourse as a 'technology of power'. In doing so, itexplores 10 mandatory textbooks of grade four and five published by Curriculum Development Centre to show what gender discourses are disseminated through these textbooks and how these discourses work as one of the strategies of power to manipulate the individual lives using Foucault's (1978) notion of discourse as a 'technology of power' (p.12). 


\section{Textbook Studies and Gender Discourse}

There have been a lot of studies around the world on gender in textbooks' context. The findings from the research vary according to the social, developmental context of the countries. The gender issues in the textbook studies found women underrepresentation in their quantity in texts in illustrations(Lee \& Collins, 2009; Barton \&Sakwa, 2012;Chick \&Corle,2016; Ullah \& Skelton, 2013), male nouns leading the female nouns in a paired noun contexts (Lee, 2018), female's space as indoor settings (Blumberg 2008; Law \& Chan, 2004; Lee \& Collins, 2010), limited females in the occupations (Barton \&Sakwa, 2012; Gharbavi\&Mausavi, 2012), female as passive (Barton \&Sakwa 2012; Blumberg 2008), and females with fewer dialogues (Ortin\& Abad 2018). These studies also claim that unlike female males were more visible in texts and illustrations, they were represented in outdoor spaces, in a variety of occupations, were presented as active individuals, and were given more voices than females confirming biased gender representation.

The studies conducted in the developed parts of the world suggest some positive improvements like the use of gender-inclusive vocabularies, gender-neutral titles for men and women, and equity in using adjectives to both men and women in Japanese textbooks (Lee, 2018). Also, the use of generic pronouns like 'they' and paired pronouns 'he/she' were used to include both males and females in Australian textbooks (Lee and Collins, 2009), and improvements in women visibility and women outnumbering men (Lee and Collins, 2010). However, gender stereotypes were still implied in the text contents despite improvements in female visibility (Lee and Collins 2008). Chick and Altoona (2006) claim that in American History textbooks have women invisibility because of their focus on politics, military, and war. The authorsargue that publishers, teachers, and students should be aware about this women underrepresentation and strive to include various resources that acknowledge women's contributions to American History. Luke (1985) claims that all texts are 'normative, shaping and constructing' (p. 19) thus a critical analysis of these texts is important to bring forward the political aspect of these texts.

Most of the studies in the textbooks use feminist stand while looking at the gender representations and often interprets its effect upon female learners (Islam \&Asadullah 2018; Barton \&Sakwa 2012). However, I believe these gender imbalances even though directly affect females limiting their access to the opportunities and personal developments, males are also not spared from this discrimination. According to Connell (2002) males also pay their prices in both of the cases either conforming the masculinity in their health risks or not confirming the masculinity in social discriminations and violence. Besides, there are psychological pressures to the 
individuals who do not confirm the traditional notion of masculinities and femininities when an individual is judged on these binary notions. In this context, this research conducted a critical discourse analysis of the textbook contents of grade 4 and 5 textbooks published by the Curriculum Development Center (CDC), Nepal.The language and illustrations are examined critically to see what kinds of gender discourses are produced in the Nepalese primary level school textbooks, and within those discourses what kind of gender knowledge and gender power relations are disseminated to the young learners.

\section{Critical Discourse Analysis and 'Technology of Power'}

Critical Discourse Analysisis a theory and also a method (Fairclough, 2001). In this research, CDA is used as a method. CDA denaturalizes the texts, unearths the textual politics that manipulates the readers in certain ways, and traces particular discourses in the texts that contribute to specific effects (Luke, 1995). CDA takes language as a social practice where unequal power relations are manifested and one of the objectives of CDA is to critically investigate these social inequalities and struggles (Wodak, 2001). In summary, CDA is a methodology that looks critically at the text contents to uncover the relation of language and representations with power. It is a critical as well as a constructive method which is used in this research to critically uncover the gender discourses hidden in all mandatory textbooks on primary level (grade 4 and 5) in Nepal.

According to Foucault (1972), discourses forms objects they talk about. This effect of discourse suggests its power. And when these discourses are internalized by the individuals these discourses work as a means of controlling those individuals which Foucault terms as 'technologies of self' (Foucault, 1980). One of the important features of Foucault's discourse discourses are the results of power and they reproduce power and knowledge as an effect that maintains the power by which it is produced. Foucault (1978) regards discourses as powerful and is capable of creating objects and events. Foucault regards discourse as 'technology of power' (p.12). 'Technology of power' refers to one of the strategies of power in which the power stops becoming a force and transforms itself into discourses and knowledge to reach in the everyday lives of individuals, their intellects, and desires to influence their ways of life in non-threatening ways. In other words, 'technology of power' is one of the approaches of power that works in subtle, non-intermediating, and covert way to control individual lives. According to Foucault, power is not repressive but, a creative force that is capable of creating discourse and knowledge. With these,power controls individuals in the most efficient way. Luke (1995) claims discourse influences individuals by constructing 
knowledge, power, and identity and is capable of position, locate, define, enable, and also regulate readers.

This research interprets the textbook representation of the gender as gender discourses which works as a 'technology of power' (Foucault 1978, p. 12). The gender discourses in the textbooks present available gender positions to the learners and shape them accordingly in those positions. Specific gender representations in the textbooks makereaders accustomed to those positions and naturalize them. The various subjective gender positions are reinforced and disseminatedthrough textbooks. If these gender discourses are disseminated through institutions like schools within organized regulations and pedagogies, they are naturalized and become a part of our life. In this research, however only textbook representation of gender in 10 mandatory textbooks of grades 4 and 5 is examined to show what kind of gender discourses and knowledge are disseminated in those textbooks published by the Government of Nepal (2008) and their potential effect on both male and female learners.

\section{Gender Representations in the Primary Level Textbooks}

There are five mandatory textbooks in each grade 4 and 5. Among them, there are five subject textbooks belonging to the Nepali language, English language, Social Studies, Mathematics, and Science. The mandatory textbooks of the entire primary level almost follow the same patterns. The analysis of these 10 mandatory textbooks somehow will represent the gender representations of similar subject contexts of other levels. The gender representations in these textbooks are presented in the following paragraphs.

In Mero Nepali of both grades, most of the chapters have males as the main character. For example, in Mero Nepali 4, chapter two "DhankoGhamanda" only narrates male gods in the story. Goddess Parvatiis mentioned in the story only when Lord Shiva tells Ganesha to ask for food from her which transforms the role of goddess Parvati into a mother and as a food server (7). In a country where the society is guided by religious superstitions, this type of representation helps naturalize the role of women as food servers and exempts men from these roles. Similarly, the illustrations of males and females are depicted in conventional get-upspromoting specific attire to them and they are presented in traditional masculine and feminine roles. Farmer is used as a maledominated occupation even though the involvement of women in this occupation is $17.8 \%$ of the total woman population in 2001 (Government of Nepal 2011). This sexual division of occupation in the textbooks is a very upsetting fact which can be seen in many instances including in 'KishaankoRahar' poem inMero Nepali 5. The poem presentsdescription of a woman farmer in the content however, the pictorial 
representation is just of a man with a plow on his shoulder (17). This cliché portrayal of the farmer as a man is found in other text parts also.

My English 4also perpetuates the traditional outfits of boys and girls in the illustrations. The reading text contains men as the main characters.For example, a landlord is a male(p. 42) suggesting a land is only owned by a male, the women are also projected in traditional roles like offering food to the guest (p. 72), in the chapter "Sports day" there are more illustrations of the boys than the girls, and the outfits of the girls are traditional which are not at all suitable for sports (p. 77). In the sports contents, the boys are only shown running (p. 81) even though the text talks about girl's participation in the race. This types of depictions of male and females in the text reinforces male domination in the leadership, ownership, activities, and sports. This also encourages a gender gap in sports participation discouraging females to take part in sports. My English 5 is discriminatory while illustrating males as a criminal (p. 5), wolf (p. 51), and big fish (p. 33). Similarly, there is a tendency of using the male pronoun 'he' for all animals.Besides, most of the reading portions have male lead characters. We can see only men as famous personalities and scientists (pp. 41-42) as if no women have been famous in the history of Nepal.It is sad to see that there are no women scientists mentioned in the chapter which is discouraging to the female students as the text lacks female role models. Both of the textbooks have very few women representations in the writers' and editors' group. This projection of both men and women is misleading as it does not represent the social progress of women and systematically uplifts the men's position and visibility through male lead chapters. Men's exclusive representation in crime is also misleading as criminals can be of any gender. Depicting only males as criminals can potentially normalize males' involvement in crimes misleading the young learners from the actual reality.

My Social Study and Creative Arts5alsoportray identical stereotypical outfits worn by men and women. The property and possessions are narrated as men's for example, "He had a big plot of land", suggesting male domination in ownerships, similarly there is no mention of a mother in the narrative (p. 8), an industrialist is a man(p. 86), among 15 national heroes, only 2 are the woman (pp. 72-77), and only men are there for the crimes, alcohol and drugs abuse (pp. 30,23,24). This projection of male and female limits female presence in the household activities suggesting a familial role as their field and questions their capabilities in other occupations and roles. On the other hand, it presents a discriminatory social structure where males are the owners, heroes, and high-rank occupations. My Social Study and Creative Arts 4 too has illustrations showing women in traditional roles (p. 44), the outfits are traditional and identical for boys and girls. Fathers are presented as decision-makers (p. 26).In lesson 2, the chapter talks about a lady teacher, but the picture shows a male teacher (p. 38). Females are 
depicted as possessions of their male family members, not as an individual identity such as, 'father's daughter' not mother's daughter, 'Sonelal's sister,' (p. 26), and 'his sister' (p. 76). Projecting females in terms of relationship restrict their individuality and agency. A statement, 'his father took a loan from the bank' (p. 26)shows the only male have agency in the family for major decisions suggesting the male dominated family structure in Nepal. This textbook also produces biased gender discourses by strengthening women's familial domestic role rather than her role in other social transformations. This questionsfemale abilities and expertise on one hand and normalizes her domestic roles in the family. Men's role in negative activities like crime, addiction also normalizes male involvement in crimes and addictions.

Generally, we take Science as a neutral, and also rational subject based on facts. So, we expect fewer stereotypes in this subject. However, this is proved wrong in the case of My Science Health and Physical Education 4as this textbook presents women in traditional roles (pp. 108, 128) in illustrations. Male domination in negative activities is maintained in this textbook as all sick individuals, smokers, injured (pp. 120, 128, 118, and 110) are males. The outfits of men and women are conventional and identical like that to those in other textbooks. My Science Health and Physical Education5 too have a similar tendency of presenting men as only diseased (pp. 95-100), alcoholic, a drug abuser, (p. 116) and wounded (p.104). Females have been shown doing traditional gender roles like using 'Dhikki, Janto' which are regarded as traditional women's works in illustrations (pp. 71-74).Bothmales and females are in identical traditional outfits and hairstyles in the illustrations.Femaleunderrepresentation can be seen in the writers' and editors' group of both textbooks.

My Mathematics 4contains, fewer stereotypes such as a traditional mother character in a traditional outfit is portrayed against a group of freely strolling men in professional getups (p. 105) in street.This suggests that a female's motherly role is the most important role for them, and males are exempted from it. In the writers and editors' group again female exclusion can be seen as there are more men and only one woman which poorly includes women in the authorship of textbook writing. My mathematics 5 has unequal gender representation on the cover page as it portraits 4 boys but only two girls confirming female invisibility. Female under-representation is maintained in the authorship of textbooks with a single female in the crowd of male writers and editors' group.

The findings from the textbooks suggested that there are imbalances in the representations of both males and females in the textbooks of all subjects. Being a different subject context where male and female representations are not much required, 
Science and Mathematics subjects had fewer gender bias in language and illustrations but, other subject textbookshad a very biased gender representation within them.

\section{Gender Discourses and Gender knowledge Suggested by the Representations}

The discourse analysis of the textbooks of grade 4 and 5 suggests biased gender discourses through the portrayal of male and female in the language and illustrations of text contents. Even though gender is not the course objectives and chapters it covertly and silently builds and disseminates discriminatorygender concepts through the representations of male and female in the text contents. For example, by depicting women in the household duties, as a mother, it suggests that household duties exclusively belong to females, and the motherly duty of women is above all duties. Similarly depicting men in the crimes, diseased, and as drug abusernormalizes male involvement in crimes. The portrayal of males and females in specific conventional costumes in textbooks suggests specific and appropriate attire for them. If the males are depicted as famous personalities, scientists, and politicians, sportsmen, and highranking jobs, the contents lack female role models and normalize male as capable of these positions. It was noticed that textbooks presented the father as the possessor of children, other relatives, and property, fathers were shown making important decisions, specific occupations were projected as males' or females', and there was a male dominancy in writer's and editor's team. When the young learners who are not yet clear about gender discriminations see these types of discriminatory representations in textbooks, they potentially internalize these ideas if they are not dealt with critically by the teachers. As these ideas are presented more or less in almost all subject textbooks, thus, even though there is no separate subject on gender, we are indirectly feeding gendered knowledge to the students through all subject contents.

Some researchers regard textbooks as a hidden curriculum disseminating gender socialization (Islam \&Asadullah 2018, p. 19; Jabeen\&Iliyas2012, p. 76; Foroutan, 2012, p. 772). According to them, gender in textbooks manipulates young children to take gender positions disseminated through the textbooks. Primary level children are very young and curious to know the world. If such identical gender roles and knowledge are exposed to the young minds, they take those roles as normalwhich can make a longterm imprint upon them. Through these textbooks, we are nourishing gender discrimination in the children. Textbook users even systematically internalize the false idea of gender which makes gender a truth rather than a social construct. Foucault(1980) says an effective combination of power is only possible when power gets access to individual bodies, their acts, attitudes, and modes of everyday behaviors 
(p. 125) in which school discipline is one of the important methods to manipulate a large group of individual. This new technology of power is not forceful but more subtle which in a hidden way to grab individual cognition and toaffecttheir ways of life. In the textbook representation of gender, circulation of stereotypical gender representations is a technology of power intended to reinforce patriarchal power relations in the learners.

The unequal representations of the gender and conventional presentation of their differences normalizes the conventional discriminations. Since young children lack a critical lens, they take the projections as knowledge and internalize the cultural differences as natural differences. Foucault (1980) says power "induces pleasure, forms knowledge, produce discourse. It needs to be considered as a productive network which runs through the whole social body" (p.119). Thus, power is a producer of our pleasure, discourse, and knowledge. In any discourse and knowledge, we can see the political stance. Representing males and females in specific ways produces power relations. Based on the finding,it can be concluded that male power is induced in negative activities, in all other public activities, and roles except familial and domestic roles. This makes male invincible in a way. However, this invincibility is also making them vulnerable to negative activities.Also, traditional masculinity is burdensome for males as it requires males to be brave, competent, fearless, strong, active all the time and the males who fail to confirm this is questioned which is of course is not justifiable.

In a country like Nepal where a male child is still preferred over a female child (Panthhe\&McCutcheon, 2015; Government of Nepal, 2011), and where women are still limited in the households, and men's doing of such works are regarded as womanly, these traditional stereotypical roles authenticates such bias attitude. It promotes superstition regarding gender and gender roles. Instead of bridging the gender gaps, it maintains the gap and potentially produces a gendered individual and unequal gender power relations. Even if most of the researcher has pointed out the drawbacks of gender representations upon women or female students, it is equally harmful tomales. The femalespotentiallyinternalize false inferiority and males internalize false superioritywhich potentially sustains a false concept concerning both males and females and maintains the gender gap.

Courtenay (2000) in his research about health and gender stereotypes, talks about the relationship of masculinity and social construction of male as the stronger sex, linked with the degenerations of the male health putting them at more health risks. Also, on one hand, males are excessively overburdened for the economic and other social responsibilities whereas, more than a half portion of the population is made paralyzed due to cultural conventions. Both genders are burdened with cultural gender conventions to fit in the society despite of their contrastive internal reality or choices. 
Moreover, gender bias in the textbooks naturalizes a false gender concept of masculine men and feminine women. This tendency also undervalues individuals who are nonbinary in terms of gender. The association of certain toys, color, emotion, outfit, manners, vehicles, roles, and activities with certain gender pressurizes and also manipulates both males and females to choose things, professions, roles, and activities according to their gender. The result upon the gender minorities can be more severe as there are no references with whom they can identify in the textbooks. This can make them feel alienated misfit in society.

This research is specific to the 10 textbooks of grade 4 and 5 subject contexts. It opens up spaces for more researches in other levels in other subject contexts. Textbooks only cannot determine to mean alone, the meaning-making from the contents depends upon how a teacher and students approache the text (Sunderland et al. 2000). Therefore, other studies involving students and teachers can bring various insights about the teaching and learning systems of Nepal. Besides gender, cultural and ethnic representations can also be explored in the school textbooks to ensure how multiculturalism is incorporated in the textbook contents

\section{References}

Barton, A., \&Sakwa, L. N. (2012). The representation of gender in English textbooks in Uganda. Pedagogy, Culture \& Society, 20(2), 173-190. doi:10.1080/14681366.2012.669394

Blair, K. D. (2002). School social work, the transmission of culture, and gender roles in schools. Children \& Schools, 24(1), 21-33.

Blumberg, R. L. (2008). The invisible obstacle to educational equality: Gender bias in textbooks. Prospects, 38(3), 345-361.

Chick, K. A., \& Altoona, P. S. (2006). Gender balance in K-12 American history textbooks. Social Studies Research and Practice, 1(3), 284-290.

Connell, R. W. (2002). Gender: Short Introductions. Cambridge: Polity.

Courtenay, W. H. (2000). Constructions of masculinity and their influence on men's well-being: a theory of gender and health. Social science \& medicine, 50(10), 1385-1401.

Fairclough, N. (2001). Critical discourse analysis as a method in social scientific research. Methods of critical discourse analysis, 5(11), 121-138.

Foroutan, Y. (2012). Gender representation in school textbooks in Iran: The place of languages. Current Sociology, 60(6), 771-787. doi:10.1177/0011392112459744

Foucault, M. (1972). The archaeology of knowledge/Michel Foucault; translated from the French by AM Sheridan Smith. In: London: Tavistock. 
Foucault, M. (1978). The history of sexuality: Vol. 1. An introduction (R. Hurley, Trans.). New York: Pantheon.

Foucault, M. (1980). Power/Knowledge: Selected Interviews and Other writings 19721977 (L. M. Colin Gordon, John Mepham, Kate Soper, Trans. C. Gordon Ed.).

Sussex: The harvester Press.

Government of Nepal. (2008). PrathamikSikshyaPathyakram 2065: Kakshya 4-5. Sano ThimiBhaktaput: Curriculum Development Centre.

Government of N (2014). My Social Study and Creative Arts 4. Sano ThimiBhaktapur:

Curriculum Development Centre.

Government of N. (1994). My Science, Health and Physical education: Grade 4. Sano

ThimiBhaktapur: Curriculum Development Centre.

Government of Nepal. (1995). My Science Health and Physical Education: Grade 5.

Sano ThimiBhaktapur: Curriculum Development Centre

Government of Nepal. (2008). Mero Nepali4. Sano ThimiBhaktapur: Curriculum

Development Centre

Government of Nepal. (2009). My English Book 5. Sano ThimiBhaktapur: Curriculum

Development Centre

Government of N. (2009). My Mathematics 5. Sano ThimiBhaktapur: Curriculum

Development Centre

Government of Nepal. (2014). My Mathematics 4. Sano ThimiBhaktapur: Curriculum

Development Centre

Government of Nepal. (2014). My Social Study and Creative Arts 5. Sano

ThimiBhaktapur: Curriculum Development Centre

Government of Nepal. (2016). Mero Nepali 5. Sano ThimiBhaktapur: Curriculum Development Centre

Government of Nepal. (2017). My English Book 4. Sano ThimiBhaktapur: Curriculum Development Centre

Gupta, A. F., \& Yin, A. L. S. (1990). Gender representation in English language textbooks used in the Singapore primary schools. Language and education, 4(1), 29-50.

Jabeen, S., \&Ilyas, A. (2012). Gender Role Modellingin Textbooks: Case Studyof Urdu Textbooksof Sindh Province. Pakistan Journal of Women's Studies, 19(1).

Khanal, S. (2018). Gender discrimination in education expenditure in Nepal: Evidence from living standards surveys. Asian Development Review, 35(1), 155-174.

Lee, J. F. K., \& Collins, P. (2009). Australian English- language textbooks: the gender issues. Gender and Education, 21(4), 353-370. 
Lee, J. F. K., \& Collins, P. (2010). Construction of gender: A comparison of Australian and Hong Kong English language textbooks. Journal of Gender Studies, 19(2), 121-137.

Luke, A. (1995). Chapter 1: Text and discourse in education: An introduction to critical discourse analysis. Review of research in education, 21(1), 3-48.

Government of Nepal, (2011). Nepal Population Report 2011. Kathmandu, Nepal: Saugat Printing Retrieved from www.mohp.gov.np/population

Sunderland, J., Cowley, M., Rahim, F. A., Leontzakou, C., \& Shattuck, J. (2000). From bias "in the text" to "teacher talk around the text": An exploration of teacher discourse and gendered foreign language textbook texts. Linguistics and education, 11(3), 251-286.

Ullah, H., \& Skelton, C. (2013). Gender representation in the public sector schools textbooks of Pakistan. Educational Studies, 39(2), 183-194. doi:10.1080/03055698.2012.702892

Uprety, S. (2016). Triple headed patriarchal hydra: Masculinities and violence against women in Nepal. Sociology and Anthropology, 4, 509-522.

Wodak, R. (2001). What CDA is about-a summary of its history, important concepts and its developments. Methods of critical discourse analysis, 1, 1-13. 